\title{
Skin Cancer Risks Avoided by the Montreal Protocol—Worldwide Modeling Integrating Coupled Climate-Chemistry Models with a Risk Model for UV
}

\author{
Arjan van Dijk ${ }^{* 1}$, Harry Slaper ${ }^{1}$, Peter N. den Outer ${ }^{1}$, Olaf Morgenstern ${ }^{\dagger 2}$, Peter Braesicke $^{2}$, John A. Pyle ${ }^{2}$, \\ Hella Garny ${ }^{3}$, Andrea Stenke ${ }^{* 3}$, Martin Dameris ${ }^{3}$, Andreas Kazantzidis ${ }^{4}$, Kleareti Tourpali ${ }^{5}$ and \\ Alkiviadis F. Bais ${ }^{5}$ \\ ${ }^{1}$ RIVM, Bilthoven, The Netherlands \\ ${ }^{2}$ NCAS, Cambridge University, Cambridge, England \\ ${ }^{3}$ DLR, Deutsches Zentrum für Luft und Raumfahrt, Institut für Physik der Atmosphäre, Wessling, Germany \\ ${ }^{4}$ Laboratory of Atmospheric Physics, University of Patras, Patras, Greece \\ ${ }^{5} \mathrm{AUTH}$, Thessaloniki, Greece
}

Received 28 March 2012, accepted 8 August 2012, DOI: 10.1111/j.1751-1097.2012.01223.x

\begin{abstract}
The assessment model for ultraviolet radiation and risk "AMOUR" is applied to output from two chemistry-climate models (CCMs). Results from the UK Chemistry and Aerosols CCM are used to quantify the worldwide skin cancer risk avoided by the Montreal Protocol and its amendments: by the year 2030, two million cases of skin cancer have been prevented yearly, which is $14 \%$ fewer skin cancer cases per year. In the "World Avoided," excess skin cancer incidence will continue to grow dramatically after 2030. Results from the CCM E39C-A are used to estimate skin cancer risk that had already been inevitably committed once ozone depletion was recognized: excess incidence will peak mid 21st century and then recover or even super-recover at the end of the century. When compared with a "No Depletion" scenario, with ozone undepleted and cloud characteristics as in the 1960s throughout, excess incidence (extra yearly cases skin cancer per million people) of the "Full Compliance with Montreal Protocol" scenario is in the ranges: New Zealand: 100-150, Congo: -10-0, Patagonia: 20-50, Western Europe: 30-40, China: 90-120, South-West USA: 80-110, Mediterranean: 90 -100 and North-East Australia: 170-200. This is up to $4 \%$ of total local incidence in the Full Compliance scenario in the peak year.
\end{abstract}

\section{INTRODUCTION}

Ultraviolet radiation (UV) from the sun can induce skin cancer. Assuming sun exposure behavior does not change, more UV will induce more skin cancer. Using chlorofluorocarbons (CFCs) and related substances (from here we will use the term ODS: ozonedepleting substance), human civilization has compromised the ozone layer that protects against harmful solar UV reaching Earth's surface (1-7). As a consequence, society has to face a

${ }^{\dagger}$ Current address: NIWA, Lauder, New Zealand.

${ }^{\ddagger}$ Current address: ETH, Zürich, Switzerland.

*Corresponding author email: arjan.van.dijk@rivm.nl (Arjan van Dijk)

(C) 2012 Wiley Periodicals, Inc.

Photochemistry and Photobiology @ 2012 The American Society of Photobiology 0031-8655/13 health risk: excess cases of skin cancer (and cataract) compared with a situation of unperturbed ozone layer. Fortunately, sustained depletion of the ozone layer is expected to have been averted by the Montreal Protocol, of which the amendments are expected to have paved the way for full ozone recovery $(8-10)$. This study aims to answer the following questions: How much skin cancer risk has been avoided by the Montreal Protocol? How much risk have we already been inevitably committed to once the problem of ozone depletion was recognized?

There are delays within the climate system, and there is a time lag from sun exposure to skin cancer development. By consequence, burden of health consequences linked to anthropogenic ODS emissions is not directly measurable today. Firstly, even when the production of ODSs is stopped, ODSs will still be emitted to the atmosphere from their banks (discarded applications). Secondly, even when ODSs will not be emitted anymore, the removal of ODSs from the atmosphere will take a substantial amount of time. Finally, people may develop skin cancer from raised UV levels they received earlier in their life, long after the recovery of the ozone layer and the UV levels. Instead of directly measuring the health risk associated with the production and emission of ODSs, we have to take all these time lags into account when formulating impact models.

In 1985, the Vienna Convention for the Protection of the Ozone Layer was agreed upon. It provided a framework for international efforts to protect the ozone layer. These efforts resulted in legally binding targets to ban ODSs, formulated in the Montreal Protocol, which was signed in 1987, with amendments in 1990, 1992, 1995, 1997, 1999 and 2005 (9). A true recovery of the ozone layer did not come within reach until the Copenhagen amendments in 1992.

In 1996, Slaper et al. (11) showed the health risk associated with different scenarios for ozone depletion. The analysis was based on trend analysis of satellite observations of the ozone layer from 1979 to 1991 . They estimated the additional risk of skin cancer for people with white skin in Europe and the United States of America for different ODS-production scenarios. They found a quadrupling of skin cancer incidence for the No-Protocol scenario by the year 2100 . This was reduced to a doubling in 
2100 for the Montreal Protocol scenario (without amendments), and even further reduced to a peak of $10 \%$ increase around 2060 for adherence to the Copenhagen Amendments.

Based on Slaper et al. (11), the assessment model for ultraviolet radiation and risk (AMOUR) was developed at the Dutch National Institute for Public Health and the Environment (RIVM): a utility suite to analyze different aspects of the production of ODSs to health-risk chain (12-15). In the past years, not only negative effects from exposure to solar UV radiation acquire attention but also positive ones: some UV is important for the formation of vitamin $\mathrm{D}$ in the skin, see e.g. (16). Vitamin $\mathrm{D}$ is important for bone strength and might help to prevent certain forms of cancer.

Since the study by Slaper et al. (11), coupled chemistry-climate models (CCMs) have advanced. They now fully incorporate the coupled nonlinear processes involved in the dynamics of the ozone layer (17-21). There is no need for ad hoc parameterizations. Recently, Newman and McKenzie (22) presented CCMbased estimates for the health impact of the Montreal Protocol. They reported a huge benefit from the Montreal Protocol for skin cancer and only minor impact on vitamin D. They also concluded that improvements of the representation of climate-relevant processes in the CCMs may lead to different results.

In this study, we start with an exploration of the "Full Compliance" scenario, the best estimate given by the WMO for production and emission of ODSs from 1900 until the end of the 21st century (scenario A1 from [8]). We start with a description of the development of the ozone layer as derived from E39C-A, see $(19,20)$ for details, followed by a description of the associated development of clouds. The AMOUR utility-suite is then used to calculate worldwide maps for the available UV dose and a scenario for skin cancer. Conclusions forthcoming from AMOUR calculations can be used to anticipate at future developments, e.g. in public health care. For the rest of this study, the combination of the AMOUR tool-suite and the CCM E39C-A will be denoted as E39C-A.

Subsequently, we make an estimate of what the world would have looked like had the Montreal Protocol not been signed: the "World Avoided." Results of the CCM UKCA $(17,18)$ are used to construct two sets of maps for total column ozone. One set is made by fitting a stationary effective stratospheric chlorine load of 9 ppbv, the load according to the WMO "No-Protocol" scenario in the year 2030. For the other set of ozone maps, which serves as a reference, a stationary chlorine load of $3.5 \mathrm{ppbv}$ is used, approximately the chlorine loading in 2000 , the year of the strongest ozone depletion. The AMOUR tool-suite is taken to estimate the associated UV climate and health risk avoided by the Montreal Protocol when compared with the reference scenario. The combination of the AMOUR tool-suite and the CCM UKCA will from now on be denoted as UKCA. This study ends with a discussion of results and a brief conclusion of which worldwide risk has been avoided by the Montreal Protocol and which risk has been committed nevertheless in the "Full Compliance" scenario. The Montreal Protocol protects life on Earth. How many lives have actually been saved by this agreement?

Combination of our population scenario with skin cancer incidence data from Parkin et al. (23) shows that by the year 2100, skin cancer incidence will be doubled in Europe and the United States of America and tripled worldwide as a consequence of aging alone. The focus of this study is on human interference with the environment and associated health impact. Therefore, this study will not address the effects of aging separately. The effects of aging will be largely eliminated by the presentation of "excess risks," the difference in risk between a scenario and a reference scenario that uses the same, aging population scenario. A similar reasoning applies to behavior. Pitcher and Longstreth (24) have analyzed cohort data collected from 1950 to 1979 for white people in the United States of America. They found that different cohorts have different melanoma mortality characteristics, showing that the construction of a health-risk scenario requires the inclusion of a behavioral component. The observed growth in skin cancer incidence is probably attributable to increased exposure. To allow for zooming in on the effects of ozone depletion, the population in the reference scenario should abide to the same behavior as in the scenario at hand. This is achieved by assuming that the UV dose received is a fixed fraction of the available UV-dose. In reality, exposure depends on behavior and behavior depends on climate, the weather, age, gender and culture. This aspect, like aging, was beyond the scope of this study.

\section{METHODS FOR THE "FULL COMPLIANCE" SCENARIO}

\section{Climate model E39C-A}

The reference model E39C consists of the dynamic part ECHAM4. L39(DLR) and the chemistry module CHEM. ECHAM4.L39 (DLR) is a derivate of the climate model ECHAM4, with an enhanced vertical resolution from 19 to 39 levels where the uppermost level is centered at $10 \mathrm{hPa}$. In E39C-A, the Lagrangian advection scheme ATTILA replaced the former semi-Lagrangian scheme in E39C, leading to large improvements in the model performance (19). The model is run with a horizontal spectral resolution of T30, corresponding to $\mathrm{ca} 3.75^{\circ} \times 3.75^{\circ}$ on the transformed Gaussian grid. The chosen time step is $24 \mathrm{~min}$. The chemistry module CHEM is based on the family concept, including stratospheric homogeneous and heterogeneous ozone chemistry and the most relevant chemical processes for describing the tropospheric background chemistry. More details on the model are found in (19).

In this study, the SCNB2d simulation performed with E39CA is used. The simulation spans from 1960 to 2049, and both anthropogenic and natural forcing are prescribed based on observations for the past and on future projections for the future. Greenhouse gas concentrations are prescribed according to the A1B scenario, and ODS concentrations are prescribed for a future scenario as expected considering the Montreal protocol (and amendments). The simulation is described in detail in (20).

\section{Ozone}

Every $12 \mathrm{~h}$, a worldwide ozone map is generated with a resolution of $3.75^{\circ} \times 3.75^{\circ}(96 \times 48$ nodes $)$. Apart from ozone maps, maps were generated for surface albedo, net shortwave radiation and snow cover. At the poles, the strongest ozone depletion of the year occurs in (local) spring, when the rising sun sublimates the ice crystals, thus releasing the collected ODS.

\section{Clouds}

The dose of solar UV radiation at the Earth's surface largely depends on cloud cover. Den Outer et al. (25) have shown that 
for European stations two-thirds of the change in total UV dose is attributable to a decline in cloud cover. We use the cloud modification factor (CMF) as a measure for cloud impact. This is the ratio of irradiance under real cloud conditions to that under cloud-free skies. The CMF is nearly zero for overcast thick clouds and is equal to one for cloud-free conditions. It includes the effects of both cloud optical depth and cloud cover.

E39C-A produced maps of cloud fraction and net shortwave radiation at the surface for clear-sky and for all-sky (i.e. including clouds) conditions. The two estimates for the net shortwave radiation were used to estimate the CMF for total solar radiation. The method of Den Outer (26-28) has been applied to convert this $\mathrm{CMF}$ for all incoming solar radiation to a CMF for UV alone. The method is a parameterization for different solar zenith angles based on pairs of observations for cloud reduction for total (global) radiation and for UV.

\section{UV}

UV calculations were made with AMOUR's radiative transfer model based on TUV (29). UV was weighted with the SCUP_h action spectrum for human skin cancer, which differs subtly from the erythemal action spectrum, see (30). The ozone- and surfacealbedo fields of E39C-A are used to estimate clear-sky SCUP_hweighted UV dose maps on a worldwide $1^{\circ} \times 1^{\circ}$ grid. The domain grid was selected to accommodate earlier calculations made with AMOUR and to connect to the available population scenario. For each grid cell, the cloud-corrected UV dose has been calculated with time steps of $15 \mathrm{~min}$, and integrated to a monthly dose. The monthly doses have been aggregated to yearly doses.

\section{Risk: new cases of skin cancer}

AMOUR includes a worldwide population scenario for the period 1900-2100. Country-specific information for a medium-fertility population development scenario from (31-33) has been combined with the LandScan High Resolution global Population Data Set for $2002(34)$, aggregated to $1^{\circ} \times 1^{\circ}$. This has resulted in a set of $1^{\circ} \times 1^{\circ}$ gridded maps of population for 17 age cohorts for ages $0-4,5-9$, etc. for the years 1900-2100.

The risk at three types of skin cancer, basal cell carcinoma (BCC), squamous cell carcinoma (SCC) and cutaneous melanoma $(\mathrm{CM})$, is estimated with the dose-effect relations from Slaper et al. (11). These relations, derived for white skin in Western Europe and the United States of America, are given in the Appendix. There it is also explained how we made them globally applicable and thereby fit for the present analysis, by taking into account differences in sensitivity for UV. Even though the ozone scenario from E39C-A stopped at 2050, our risk analysis with E39C-A was extended to the year 2100. Our assumption that after 2049 the annual UV dose will remain constant will not have affected our results for the second half of the 21 st century significantly, firstly since in this period of time, according to the scenario at hand, depletion of the ozone layer is largely compensated for and secondly because exposure in the second half of the 21 st century is not dominant for the risk in this same period: in average sense, there are several decades of delay between the induction of DNA damage by ultraviolet radiation and the expression of the associated mutations in skin cancer.
To demonstrate the health impact of the "Full Compliance" scenario, we compare the associated development of skin cancer incidence with that for a reference scenario. The difference in incidence between a scenario and the reference scenario is called the excess incidence. For the reference, it is assumed that, for the whole period considered, both ozone layer and clouds have been and will be unaffected (by both natural and human interference). This means unaltered and stationary ozone- and cloud climate, with only an annual cycle. This "No Depletion" scenario has been based on the 10-year mean annual dose from 1960 to 1969, as estimated with E39C-A. The population scenario for the reference run is the same as for the full E39C-A run.

\section{METHODS FOR THE "WORLD AVOIDED” SCENARIO}

Unlike with the "Full Compliance" scenario, we do not make a dynamical analysis of the "World Avoided" scenario. Instead, two time slices for (ozone maps of) the Earth are created for 10 years with different effective, stratospheric chlorine loads: one for the year 2000, with a load of $3.5 \mathrm{ppbv}$ and one for 9 ppbv, the load projected by WMO for about the year 2030 if the Montreal Protocol had not been implemented. The health damage that would be caused by the latter scenario would develop explosively, albeit with the earlier mentioned delay of some decades after exposure to the harmful UV. Newman et al. (35) tried to make such a dynamical run with a climate model to about 2060 with exponentially increasing chlorine. After a while, the stratosphere contained so little ozone, that the model was not prepared to handle the extreme condition and gave up. These are the reasons why we have not made a dynamical scenario analysis to estimate the gain made by the Montreal Protocol.

\section{Climate model UKCA}

The UKCA model is based on the Met Office Unified Model (MetUM). The model is run at a resolution of $3.75 \times 2.5^{\circ}$ $(96 \times 73$ grid nodes) with 60 hybrid height levels in the vertical, extending to $84 \mathrm{~km}$. There is a representation of nonorographic gravity waves. AMIP2 sea-surface temperatures (SSTs) and sea ice are prescribed from the period September 1989 to August 1999. Ocean feedback is important to climate, especially on long timescales. We focus here on relatively short periods ( $\mathrm{ca}$ three decades) where the limitation of using prescribed SSTs is less serious. We have added to the MetUM a stratospheric chemistry scheme. We use a nonfamilies solver and prescribe sulfate aerosol surface area densities. Two runs are made with the UKCA model: a reference run, using the present-day chlorine loading of $3.5 \mathrm{ppbv}$, and a "World-Avoided" run, using 9 ppbv of chlorine, the concentration corresponding to the no-protocol scenario in the year 2030. Both simulations assume a contemporary bromine loading of 20 pptv. For chemistry, long-lived tracers and halogen source gases are given uniform and timeinvariant lower boundary conditions representative for the 1990s, except for the CFCs, which are increased in the 9 ppbv simulation. For radiation, time- and spatially invariant fields (identical in the two simulations) are assumed for all greenhouse gases except $\mathrm{O}_{3}$ and $\mathrm{H}_{2} \mathrm{O}$, with numbers representative of the 1990 s. The same SSTs and the same radiative forcing due to greenhouse gases (including CFCs) was assumed in both runs, implying that climate change has not been factored in. The present-day run 
compares well with observations. Details of the model are described in reference $(17,18)$.

\section{Ozone and clouds}

For the construction of ozone fields, data derived from the CCM UKCA are used just like E39C-A. The maps produced in this way are worldwide with a resolution of $3.75^{\circ} \times 2.5^{\circ}(96 \times 73$ nodes $)$ and estimated for each month in a period of 10 years. Cloud impact and surface albedo were not estimated by UKCA. Instead, we used climatologic estimates for cloud impact and surface albedo for each month of the year, on basis of satellite observations.

\section{UV}

For both UKCA model runs, monthly and yearly worldwide, SCUP_h-weighted irradiance maps are constructed with a $1^{\circ} \times 1^{\circ}$ resolution, in the same manner as carried out for the Full Compliance scenario. For each run, the 10-year dose maps were aggregated to get a mean year dose estimate.

\section{Risk}

We estimated how many new cases of skin cancer would appear annually in the respective scenarios. This was done on basis of the yearly UV irradiance dose maps in the same way as for the Full Compliance scenario. Seventeen age cohorts are discriminated with cohort width of 5 years for people in age from 0 to 85 year. There were no UKCA-model estimates for the thickness of the ozone layer before 1980, the era in which the dose contributions were received that dominate the reference incidence numbers with which the dose-effect relations are calibrated. To overcome this lack of information, the ratio of the UV dose in 1980 and in 2009 for the Netherlands is estimated using AMOUR with total ozone measurements from satellites (dose ratio 0.92) and this ratio is used as a basis for a correction factor in the dose-effect relations. The resulting age-specific incidence maps are combined for three types of skin cancer with the age-specific population maps for the year 2030 from the population scenario presented by Struijs et al. (15), to estimate the total difference in skin cancer incidence. In this analysis, the reference is formed by the UKCA model with stratospheric chlorine load for the year 2000. This is near 1995, the time when total column ozone in the real world, following the Full Compliance scenario, reached its minimum. The use of this reference makes our excess risk estimates into conservative estimates for the excess risk for the World Avoided scenario when compared with the Full Compliance scenario.

\section{RESULTS FOR THE "FULL COMPLIANCE” SCENARIO}

\section{Ozone}

Figure 1 shows modeled time series for total column ozone for local spring (October for the southern hemisphere, April for the northern hemisphere), averaged over zonal bands with a bandwidth of $11.25^{\circ}$ (eight bands for the southern hemisphere). Ozone values derived from E39C-A show a high bias of about $50 \mathrm{DU}$, but the general features and behavior are in agreement with observations (see [21] and [36] for a specific discussion about the bias). We have not renormalized ozone estimates from E39C-A to match satellite observations because E39C-A is highly nonlinear. This means that ozone fields that would be matched to observations, either by multiplication with a correction factor or by subtraction of a fixed term, would not be consistent with the climate model anymore.

Two dotted lines are added in Fig. 1, one for the zonal band on the southern hemisphere with the highest column ozone $\left(-51^{\circ}\right)$ and one for the band with the lowest column ozone $\left(-84^{\circ}\right)$. These curves were constructed using the method used by Slaper et al. (11), which combines a trend analysis of global satellite-based measurements for 1980-1990 with parameterizations of dynamical effects in the ozone layer for the remaining period 1991-2100. The first thing to notice is the good qualitative agreement. The time when the Antarctic ozone hole will start its recovery matches: for both solid (present analysis) and dotted (1996 method) lines, depletion is at its worst around 1995. The E39C-A results suggest an earlier recovery of the ozone layer than suggested by Slaper. For the extra-polar regions, this can be the result of the inclusion of climate change in E39C-A. Increasing greenhouse gas (GHG) concentrations in the model lead to stratospheric cooling and thus a slowdown of the catalytic reactions for ozone destruction. Over Antarctica, additional cooling will promote ozone depletion as more polar
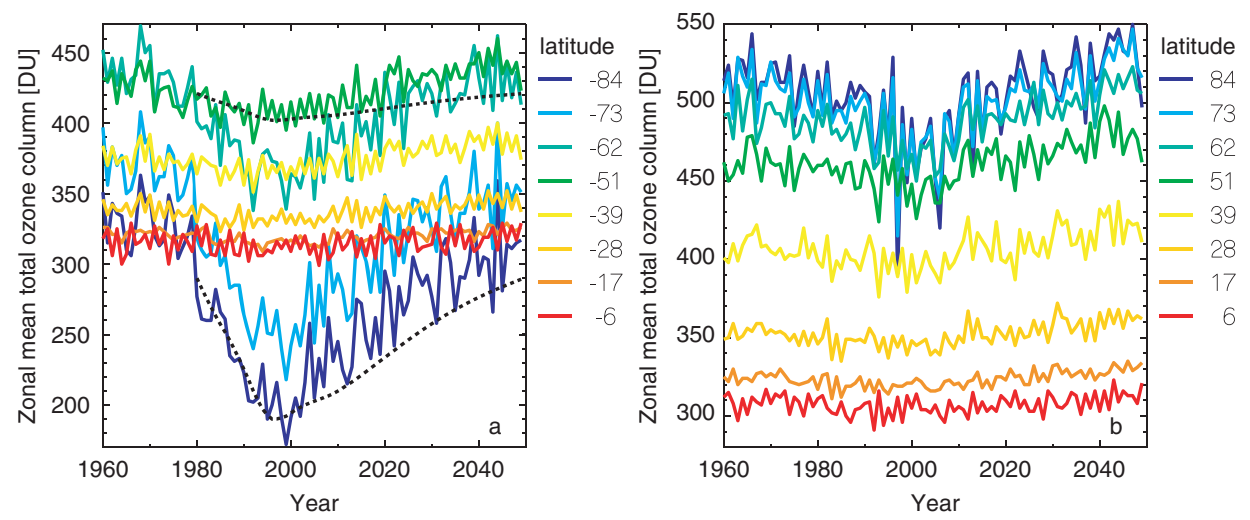

Figure 1. Modeled total column ozone for local spring in the Full Compliance scenario according to E39C-A (left: October, southern hemisphere; right: April, northern hemisphere). Total column ozone has been averaged over $11.25^{\circ}$ zonal bands (midpoint latitude is shown). Dotted lines give the ozone scenarios for latitude bands $-84^{\circ}$ and $-51^{\circ}$ based on the method used by Slaper et al. (11) and calibrated with the (modeled/observed) total column ozone estimates from 1980 to 1990 from the respective models. 
stratospheric clouds (PSC) will form, overcompensating the slowdown of gas-phase ozone depletion which follows the heterogeneous chlorine activation on PSCs. E39C-A simulates the temporal and latitudinal structure of the ozone hole until 2010 mostly in agreement with observations (37), but the return date is earlier than in most other models.

\section{Clouds}

In Fig. 2, the zonally averaged CMF for UV in June (summer) and December (winter) for eight bands on the northern hemisphere is presented. The curves have been smoothed with a 5 year central moving average (boxcar filter). There is a general tendency for the CMF to either remain (stochastically) stationary or to gradually drop to lower values, which means "stronger cloud-impact." The largest change in CMF is observed in December for the $62^{\circ}$ latitude band: from 0.7 in the year 1960 to 0.58 in the year 2049, a decrease of $17 \%$. Trends in CMF from E39C-A in summer are less manifest than in winter. The June graph for the $51^{\circ}$ latitude band shows an increase in cloud transmission, the others do not show a change or a decline.

\section{UV}

According to analysis with E39C-A of the "Full Compliance" scenario, ozone in the northern hemisphere will recover to 1980 values between 2010 and 2020, whereas at the same time, clouds will tend to have a stronger reducing effect on UV radiation. To assess which of these two effects is dominant, time series of clear-sky and cloud-corrected zonally averaged annual UV radiation are presented in graphs (a) and (b) in Fig. 3, relative to the annual UV dose in 1960. Graph (c) depicts the isolated development of the cloud impact compared to the cloud impact of 1960 (the ratio of the second graph to the first graph). It shows that cloud impact will remain more or less the same for the zone from latitude 20 to $50^{\circ} \mathrm{N}$, but in the tropics and north of $50^{\circ} \mathrm{N}$ latitude, clouds will transmit increasingly less UV. Curves in Fig. 3c show some scatter, but this trend is manifest over the full time domain. The development of UV radiation under clear sky, in graph 3(a), reflects the associated temporal development in the ozone layer shown earlier in Fig. 1: initially, ozone depletion will lead to more UV for the midlatitudes and near the poles (1970-2000). Subsequently, ODSs will leave the stratosphere and allow for a restoration of the ozone layer. Enhanced greenhouse gas concentrations will cool down the stratosphere and induce recovery (and above) of the ozone layer and reduce UV to smaller than 1980 levels. The impacts on UV change from ozone and from clouds are comparable in magnitude.

\section{Uncertainty analysis of UV climate}

Recently (10,37), "Full Compliance" scenarios for ozone and UV radiation climate have been presented for an ensemble of CCMs, including E39C-A and UKCA, the models used in our analysis. For the northern midlatitudes, Fig. 2-6 in the UNEP/ WMO Scientific Assessment of Ozone Depletion 2010 (10) suggests recovery of the ozone layer to undisturbed conditions between 2016 and 2026 ( $\pm 2 \sigma$ range), with an ensemble spread from 2008 to 2050 . For the midlatitudes on the southern hemisphere, ozone recovery is estimated to come about a bit later: between 2030 and 2040 (ENSEMBLE spread from 2012 to 2048). In the ensemble of CCMs, E39C-A shows a relatively early return of ozone to recent (undisturbed) levels. This difference may be related to the location of the upper model boundary, which is centered at $10 \mathrm{hPa}$, whereas the majority of CCMs reach up to the mesosphere $(0.01 \mathrm{hPa})$. The ozone bias of about $+50 \mathrm{DU}$ in the E39C-A results, will induce a systematically attenuated UV climate.

Estimates of shortwave radiation at the surface provided by CCMs, both under clear- and all-sky conditions, are approximations because they are computed from a broadband radiative transfer model. This approach has not been exhaustively evaluated, particularly with respect to the description of clouds ([20] chapter 3, [38]). According to Bais et al. (37), the CMF calculations depend less on the accuracy of the radiation schemes employed in the CCMs, and more on how clouds and their effects on radiation are represented in each model. The uncertainties in the CMF deduced by E39C-A are expected to be similar to those in other models discussed in Bais et al. (37); however, no clear statements can be made about the quality of E39C-A results with respect to cloud effects. In that study, it is concluded that: "Cloud effects are responsible for $2-3 \%$ of the reduction in

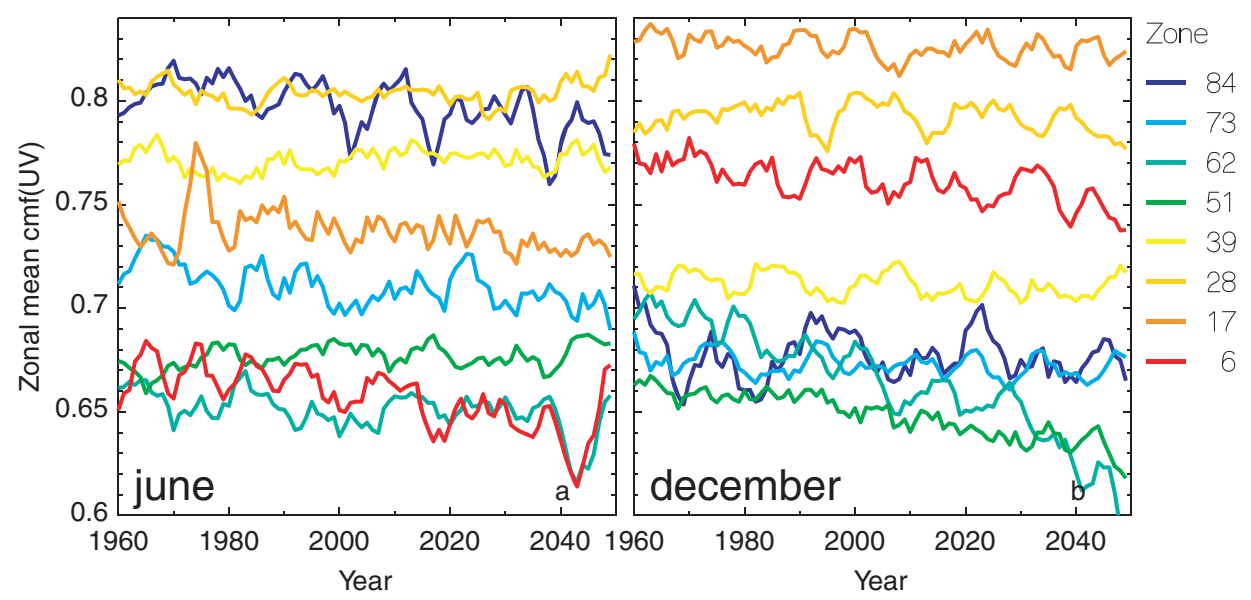

Figure 2. Zonal mean cloud modification factor for the Full Compliance scenario from E39C-A for UV for the months June (a) and December (b) for the northern hemisphere. The number in the legend refers to the mean latitude in $\left[{ }^{\circ}\right]$ of the zonal band. 

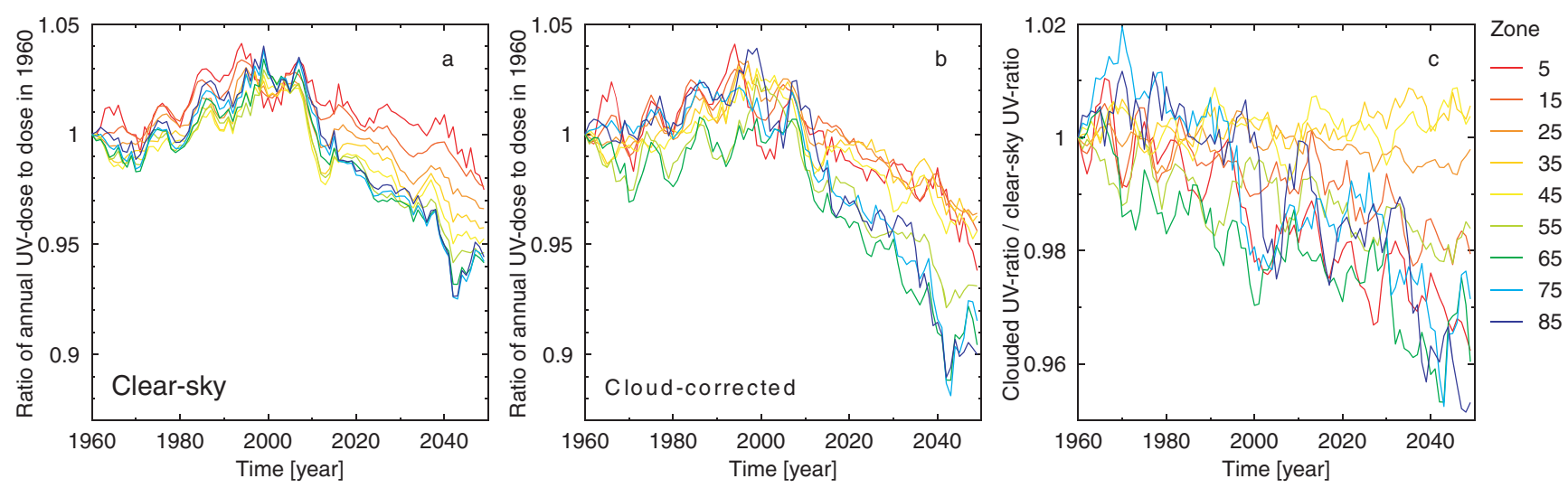

Figure 3. Ratio of annual UV dose to UV dose in 1960, estimated with E39C-A. (a) clear-sky dose, (b) cloud-corrected dose, (c) ratio of the graph (b) to (a). This gives the development of the cloud impact. The annual UV dose has been averaged over zonal bands with zone width of $10^{\circ}$.

erythemal UV at high latitudes, but they slightly moderate it at midlatitudes ( $\mathrm{ca}$ 1\%)." Both the ensemble of CCMs and the specific model that have been used indicate a trend (1960-2100) in cloud impact ("more cloud") that is in the opposite direction when compared with the observational results (1980-2006) reported by Den Outer et al. (25) ("less cloud"). The 2011 report from the UNEP (16) indicated that cloud cover would increase at northern high latitudes (and UV decrease), but would be less in the tropics (and thus a UV increase).

\section{Risk: new cases of skin cancer}

Estimates for excess total skin cancer incidence are given for eight regions shown in Fig. 4: New Zealand, Patagonia, Congo, China, North-East Australia, Mediterranean, South-West USA and West Europe. These regions have been selected to demonstrate the variety of our results for different populations. Regions were selected such that intraregional variation in the population (which itself was modeled to be a composite of different ethnic groups) was small and that variation in latitude (and therefore UV-dose) would not dominate intraregional variance in risk. See the Appendix for details on the population scenario.

In Fig. 5, the excess total incidence is shown for the sum of three types of skin cancer in the Full Compliance scenario. All estimates are dominated by $\mathrm{BCC}$ incidence, as that is the most prevalent type of skin cancer. The maximum of the excess incidence (compared with the "No Depletion" scenario) is in the following ranges: New Zealand: 100-150, Congo: $-10-0$, Patagonia: 20-50, Western Europe: 30-40, China: 90-120, South-West USA: 80-110, Mediterranean: 90-100 and NorthEast Australia: 170-200, (in extra cases skin cancer per million people per year). This is up to $4 \%$ of the local total incidence in the peak year.

The largest excess incidence rates are found for Australia, closely followed by New Zealand. These countries are relatively close to the Antarctic ozone hole, where the strongest ozone depletion is manifested. Figures 1 and 2 show that, for the associated latitudes in comparison with other latitudes, ozone has just modest and CMF only marginal development over the observed period. This excludes the ozone hole from being the cause of the large excess incidence rate. A factor, that may explain the dominance in Fig. 5 of Australia and New Zealand, is that people from Australia and New Zealand, with their predominantly white skin, are relatively sensitive to UV, compared with other people living in the tropics, and by consequence relatively sensitive to changes in ozone. Furthermore, they have a high life expectance. This gives damage inflicted by UV the time to mature relatively long into a malignance, whereas simultaneously the life-integrated dose of UV received continues to grow. The higher elevation of the sun in Australia leads to a higher reference rate for the incidence of skin cancer, such that the absolute effect of a small change in UV index is larger in Australia than in New Zealand.

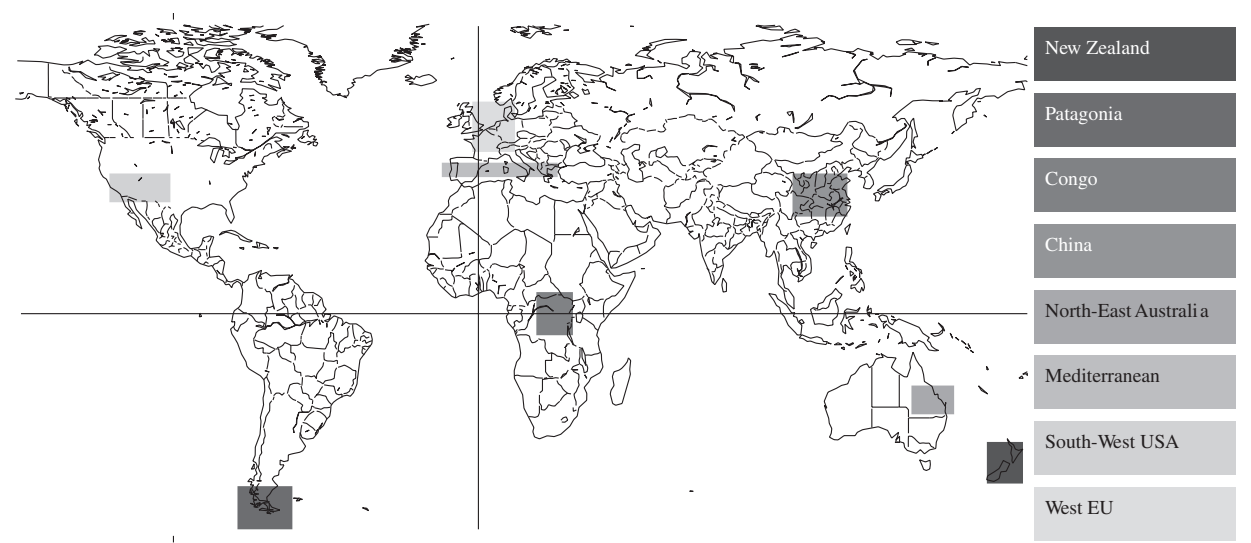

Figure 4. Regions for which the excess risk at skin cancer is reported. 


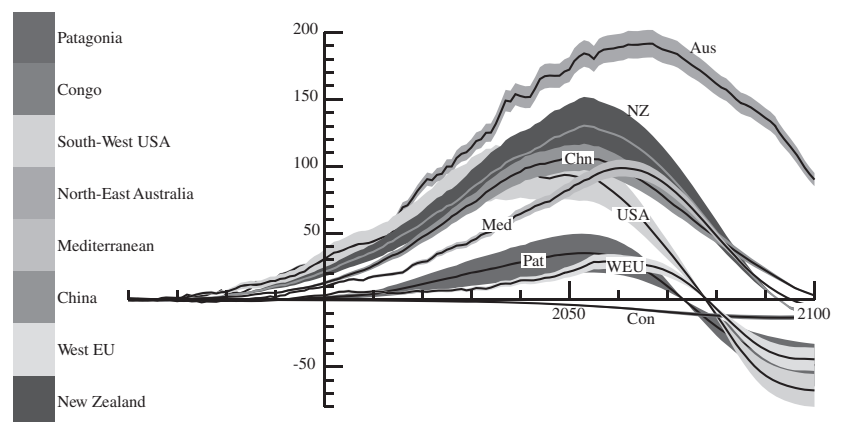

Figure 5. Excess risk at skin cancer $(\mathrm{BCC}+\mathrm{SCC}+\mathrm{CM})$ in the Full Compliance scenario when compared with the No Depletion reference scenario, estimated for eight regions, with 1-sigma intervals based on interpixel variation.

In all cases, the incidence peak is decades later than the peak in the ozone depletion plus associated UV exposure. The maximum of the number of new cases of skin cancer is halfway down the 21 st century, when the ozone layer in these calculations has already recovered. The cause of this delay is that to become a(n excess-) malignance, any (excess-) damage that is sustained first has to go through some stages of development. Another cause is that the total damage done by UV will increase in the course of someone's life with increased exposure. This makes skin cancer (partly) a disease that tends to come to expression later in life.

\section{Uncertainty analysis of risk}

For each region, interpixel variations in incidence rates are used to make an uncertainty analysis. The estimated tolerance thus reflects only one component of uncertainty in the whole chain from ODS to health risk. In a Monte Carlo procedure, Slaper et al. (11) have shown that uncertainty in the dose-effect model parameters makes health-risk assessment associated with ozone depletion to be an order of magnitude analysis, i.e. up to a scaling factor in the range 0.1-10. Error estimates for excess health risk for different regions or scenarios are, however, correlated. This means that one should project the overall uncertainty in the integrative health assessment on the extent of the vertical scale shown in risk plots; qualitative characteristics and differences between scenarios or regions in such plots can still be significant.
The attenuation of the UV climate that resulted from the bias in ozone estimate, does not necessarily affect our risk estimates. The factors $b$ in the dose-effect relations (given in the Appendix) are determined by imposing the relations to yield the observed reference incidence for the reference point. As long as the same biased UV estimator is used for both the risk assessment in the scenario analysis and for estimating the multiplicative factors $b$ via the reference conditions, then any constant bias factor in the UV estimate is canceled. In case the ozone bias would be latitude dependent, then the consequences for our risk estimates would still be relatively small. Both the risk calibration and the majority of the regions with the largest contributions to the (changes in) risk are found in the northern midlatitudes. Clear exceptions are Australia and New Zealand.

\section{Risk: taking into account duration and severity of the} diseases life-years lost

Each form of skin cancer entails its own unique loss of quality of life (see [15] for specifications). Incidence rates do not take this into account: they merely count cases. Of all types of skin cancer, melanoma will contribute the most to the loss of lifeyears attributable to ozone depletion (39). As for incidence, the excess mortality peak will happen halfway this century. At that time, ozone depletion will cost around eight life years per million West-Europeans annually, associated with an annual addition of around 30 new cases of skin cancer.

\section{RESULTS FOR THE "WORLD AVOIDED" SCENARIO}

\section{Ozone and clouds}

Closer inspection of the ozone fields shows that UKCA, just as E39C-A, has a high bias leading to overestimation of the total column ozone.

\section{UV}

Absolute and relative differences of the mean year dose UV in the "World Avoided" when compared with modeled present-day conditions are presented in Figs. 6 and 7. As can be expected, the ozone hole above Antarctica is huge for the World Avoided.

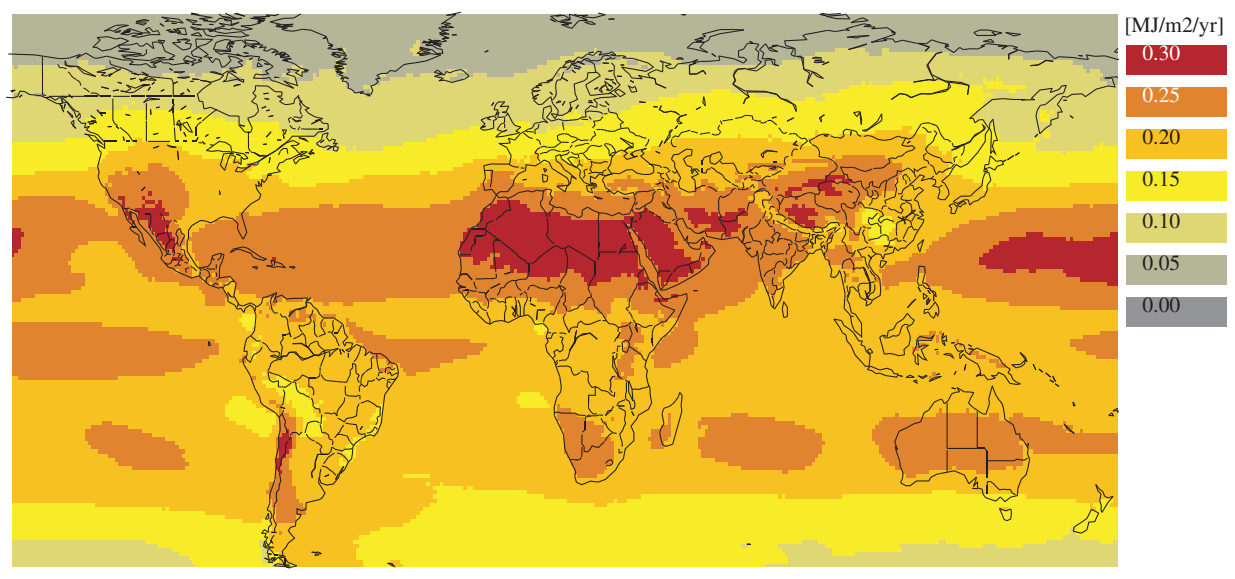

Figure 6. Absolute differences in year dose $\mathrm{UV}\left(\mathrm{MJ} \mathrm{m}^{-2} \mathrm{year}^{-1}\right)$ between the World Avoided and the modeled present-day conditions. 


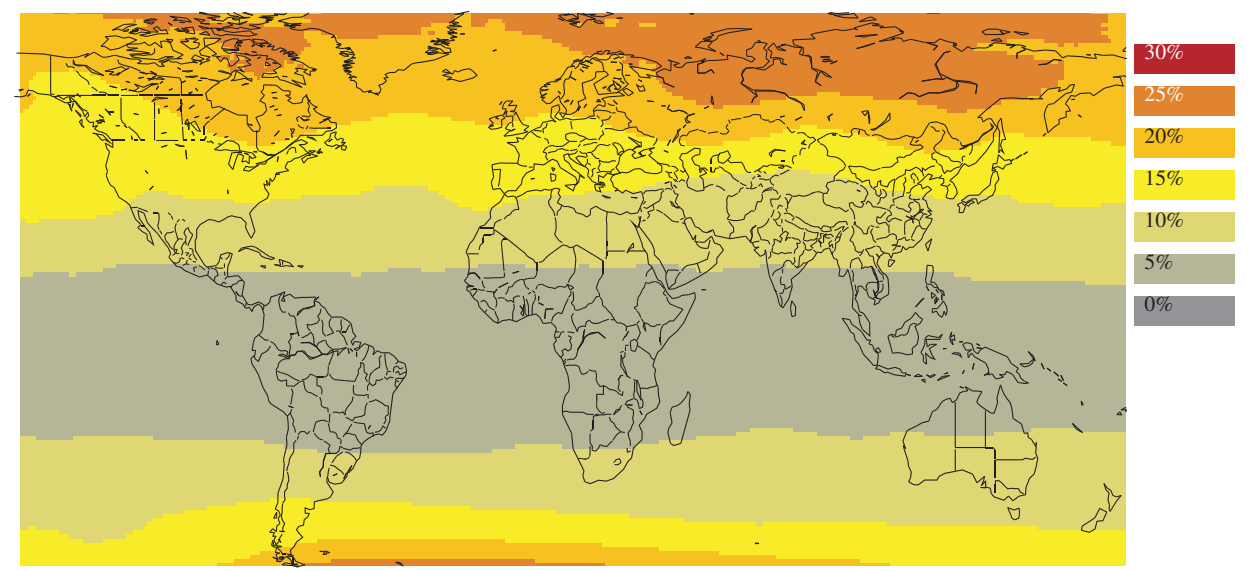

Figure 7. Relative differences in year dose UV between the World Avoided and the modeled present-day conditions.

Our main goal is a risk assessment; as not many people live in the South Polar region, that part of the world is not shown, allowing for zooming in on the regional differences in the rest of the world. The largest relative difference is found near the poles, but the annual dose in that part of the world is quite small. The largest absolute difference is (apart from in the South Polar area) found in the subtropics. People with the most sensitive skin type live in the midlatitudes and in the north, so the distribution of the increase in UV spares the more vulnerable groups.

In this study, two different CCMs are used to answer two different questions. To assess the impact of the choice of CCM on our results, estimates from both models are compared for the annual, clear-sky UV dose in Fig. 8. For UKCA, the mean value of the annual dose is used over the whole low chlorine scenario (3.5 ppbv). For E39C-A, the UV dose in 1997 is taken, when the chlorine content is the largest: 3 ppbv (see (19), their Fig. 8). In comparison with UKCA, the E39C-A-dose is relatively low in the tropics $(-15 \%)$. This is related to the lower chlorine load: 3 ppbv vs 3.5 ppbv. The UV dose is relatively high near the poles. In the midlatitudes, the two model estimates more or less agree. The pattern of the differences may partly be related to the use of a single year for E39C-A. A mean value over, say, 5 years would reduce this source of noise, but then the chlorine load of the associated contributions would be even lower than now. Not many people live close to the poles and people in the tropics tend to have lower UV sensitivity. We therefore do not expect significant impact from model choice on our risk estimates.

\section{Risk}

For the year 2030, the grand total difference in skin cancer incidence between the World Avoided and the Full Compliance scenario's amounts to two million cases of skin cancer per year, $14 \%$ of the total incidence in the "World Avoided" scenario, that will not appear because the Montreal Protocol and its amendments have been implemented. Figure 9 shows the geographic distribution of the number of cases saved per million local people. The largest peaks are found in the south-west of the United States of America and in Australia: a prevention of up to 1500 cases per million people per year, a very large number. Furthermore, an appreciable gain is shown in Europe, the United States of America, Canada, Argentina and Russia: an annual amount of about 600 people per million in these countries will not develop skin cancer because CFC production and emissions have been regulated. This is $25 \%$ of the total skin cancer figure from the UKCA baseline scenario for these regions for the year 2030 .

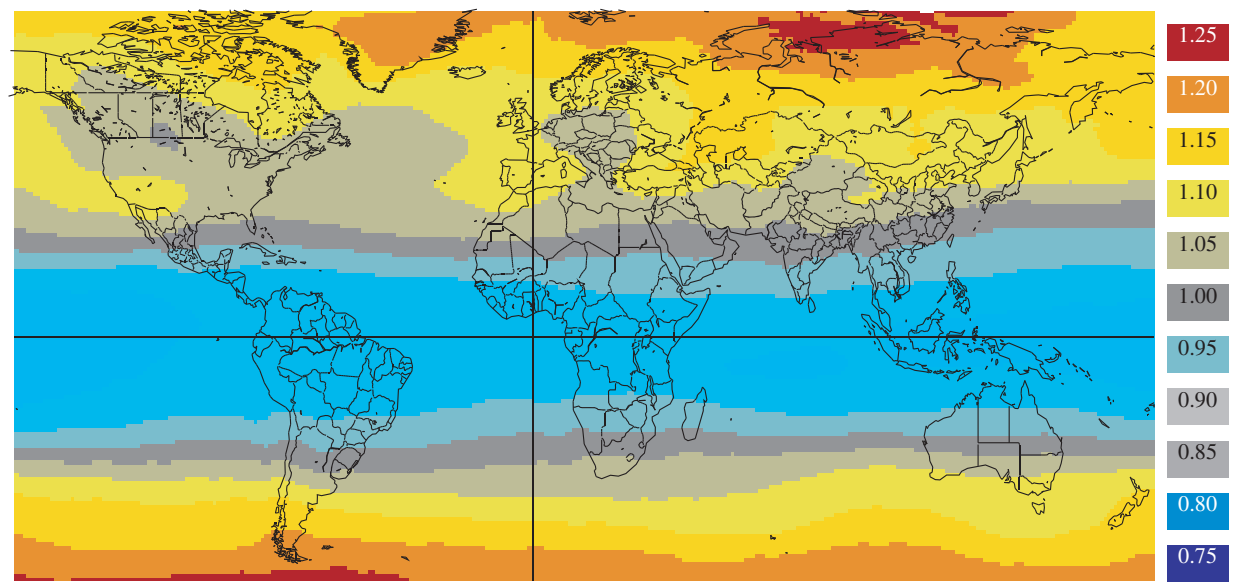

Figure 8. Ratio of annual clear-sky UV dose for 1997 from E39C-A (3 ppbv) to the mean value of the low chlorine run from UKCA (3.5 ppbv). 


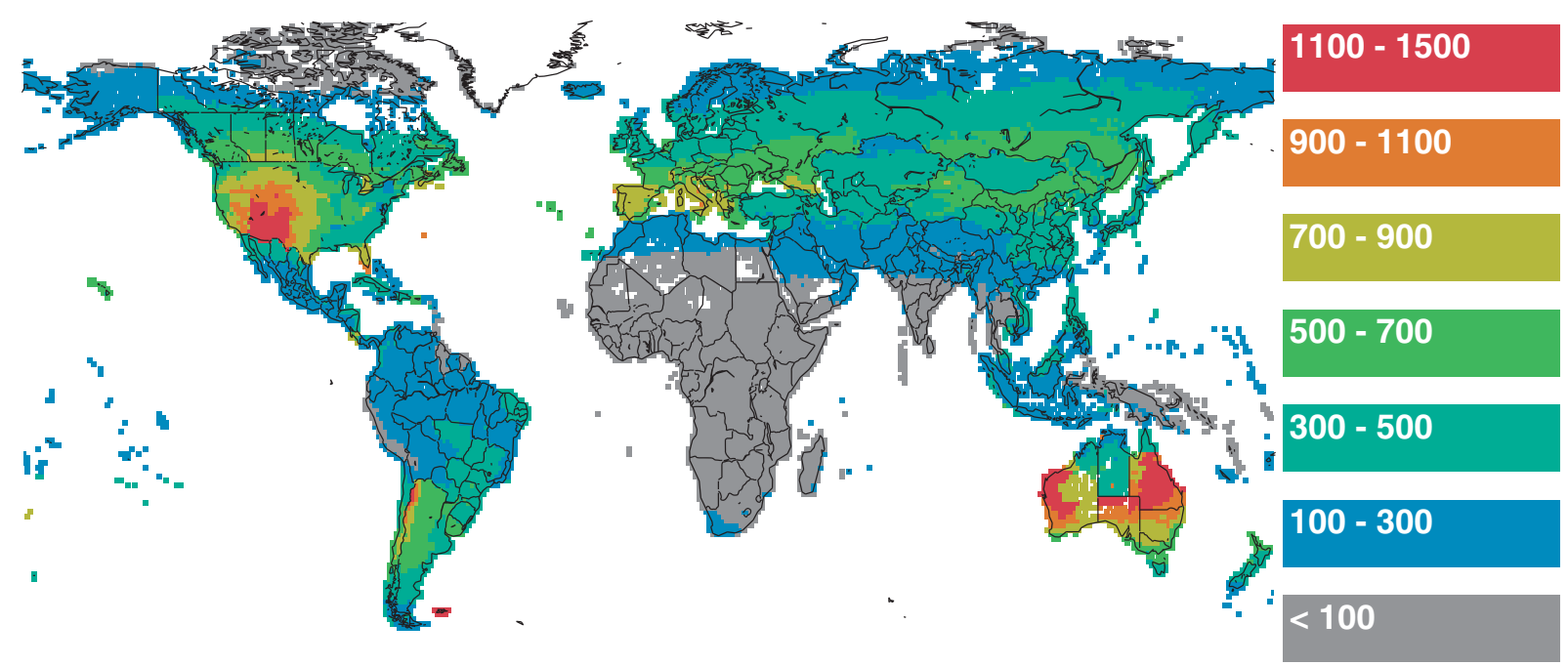

Figure 9. Total numbers of new cases of skin cancer per million people per year avoided by the Montreal Protocol in the year 2030.

In reality, the "World Avoided" scenario would come about gradually, so our analysis has its limitations. The analysis has been made with use of the available climate model runs.

On the one hand, this risk analysis is an order of magnitude analysis because in reality the change in ozone and health response function would have happened gradually over many years. On the other hand, this kind of experiments allows a clearer attribution of cause and effect.

\section{DISCUSSION AND CONCLUSIONS}

What has been the additional value of using CCMs in this study? The dynamical evolution of the ozone layer is dealt with from first principles, instead of using heuristic parameterizations of ozone amounts. However, in the comparison of time series for zonally averaged total column ozone, estimates from Slaper et al. (11) showed a remarkable resemblance with CCM results. Despite 25 years since the adoption of the Montreal Protocol and the evidence that global ODS levels are now declining, there continues to be observed ozone depletion, with the winter of 2010/2011 actually showing the largest loss in the Arctic on record (40). Figure 1 shows that the time series for zonally averaged total column ozone exhibits a sufficient amount of oscillation (e.g. from equatorial quasi-biennial oscillation of the zonal mean wind) to let this observed arctic ozone hole and our model remain well in agreement with one another.

Commonly, models have systematic biases with respect to observations. Here, both models have generally a positive total column ozone bias for the recent past with respect to satellite observations from e.g. TOMS. Therefore, continued UV and ozone observations are required to benchmark models and to scale their results for impact studies like ours. However, note that the models' ozone bias does not adversely affect our results because the doseeffect relations have a functional dependence on UV exposure for the number of skin cancer cases. These relations are calibrated by adjustment of a multiplicative constant such that the observed number of incidences is obtained for present-day conditions.

Den Outer et al. (25) have shown that, for a set of observatories in Europe, the origin of the observed increase in UV dose has a signature linked to cloud changes. E39C-A demonstrates an increase in cloud impact, contributing to a declining UV trend.
Model and measurements disagree. A possible explanation is that observations show a regional brightening in Europe recently, caused by reduced emissions of $\mathrm{SO}_{2}$. Via a cloud-aerosol feedback, this results in a reduction of cloudiness. Global stratospheric CCMs generally do not have the physics and chemistry in place to represent this. It would be interesting to see whether this effect can be reproduced by the AR5 models (candidates for evaluation in the Fifth IPCC Assessment Report, scheduled for 2013).

In certain cases, the estimated excess incidence rates become negative after a while. This is caused by climate change due to increasing GHG concentrations, which is taken into consideration in the Full Compliance scenario. This climate change affects ozone and the CMF. A major factor here is the speedup of the Brewer-Dobson Circulation, which takes ozone from the tropics to high latitudes. Correspondingly, there will be less ozone in the tropics and more in mid- and high latitudes. Superimposed on that, enhanced GHG concentrations will lead to global warming of the troposphere (i.e. the greenhouse effect) and to a decrease in temperature in the stratosphere, thus slowing down the gas phase photochemical breakdown reactions of ozone. Furthermore, increasing methane will lead to more stratospheric ozone. In the reference runs, these dynamical effects are not taken into account, and consequently these runs do not exhibit the temperature-driven increase in ozone. In this way, climate change accelerates the ozone layer recovery and may lead to a super-recovery (10).

Slaper et al. (11) estimated an excess incidence for the Full Compliance scenario (related to the No Depletion scenario) of $+[25-147]$ cases per million per year for Western Europe in the peak year. This corresponds well with the present analysis: $+[30$ -40] cases per million per year. It must be noted that E39C-A projects a relatively early ozone recovery in comparison with other CCMs. An ensemble approach may well support the full original risk range.

For the World Avoided in 2030 in Southern Australia and New Zealand, Newman and McKenzie (22, their Fig. 4) estimate an increase in local noon UV index in summer from 13 to 16 $(+23 \%)$. This is twice as much as the $10 \%$ increase in year dose that is found with UKCA in Figs. 6 and 7. In consequence, our estimates for health consequences will be more modest than in the analysis by Newman and McKenzie. Newman and McKenzie 
erroneously report the mortality for Australia and New Zealand in the World Avoided too large by a factor of 100. Furthermore, they use dose-effect relations in a linearized form (variations around a reference state are estimated via the derivative of the dose-effect relation), but the reported factor of 3 with which the peak UV dose for midlatitudes would be changed if the ozone layer would be depleted to zero, is not "order 1" and therefore does not allow for a linearized approach: higher order derivatives play an essential role.

Skin reflectivity has shown to provide a good proxy for protection against skin cancer from UV (see Appendix). In locations with abundant UV, a darker skin tends to develop than in locations with low UV. In principle, it is not excluded that this mechanism can be activated by a changing UV climate, e.g. as a reaction to ozone depletion, but according to the model by Jablonski and Chaplin (41), this takes many generations. The result would be a slightly darker skin with lower susceptibility for UV. There is no scientific insight yet if the skin works this way. In addition, it would be possible that this self-adapting UV sensitivity would lag some time behind the relevant climate changes, allowing room for the harmful extra UV to first induce negative health implications before it is mitigated by nature. Migration can lead to a geographic redistribution of skin reflectivity over a much shorter period, but this has been out of our scope.

Many groups are working hard on vitamin D dynamics, but it was too early for us to include an estimate of the possible average raise in vitamin $\mathrm{D}$ level in blood serum as a reaction to UV climate hardening induced by ozone depletion. UV can also induce cataract. Uncertainty in the dose-effect relation has been considered to be too large to allow for inclusion of cataract in our account of ozone depletion-related health impact. Struijs et al. (15) have shown that UV-related cataract may become a critical problem in the developing countries.

This study is the first integrated attempt to use CCM results in UV radiation and risk models in a full global scenario analysis. Many uncertainties exist, especially with respect to the influence of the combined effect and mutual interaction between climate change and ozone depletion and recovery. In addition, exposure habits can and will change over time and thus influence future skin cancer risks. Nevertheless, this study gives a state of the art scenario analysis of the successes of the Montreal Protocol and its amendments in reducing future excess skin cancer risks associated with global ozone depletion. Models support policy developments, but continued effort is required to assure full global compliance of the MP and its amendments. It is also vital to continue ozone and UV-monitoring in view of the many scientific uncertainties on the interaction with effects of climate change. Furthermore, local or regional deviations from the overall patterns cannot be excluded.

This study shows that the Montreal Protocol and its amendments have an obvious beneficial effect regarding a clear reduction in skin cancer risks. Had no countermeasure been taken to save the ozone layer, then about two more million people per year would have developed skin cancer by the year 2030, an increase of $16 \%$ worldwide, when compared with the future that is the result of the Montreal Protocol and its amendments. Estimates for the remaining excess risk, that is associated with the use of ODSs and that had already been unavoidably committed when the Montreal Protocol was framed, show a scenario with a peak in the excess incidence somewhere mid 21st century, the height of the peak is $+2 \%$ for E39C-A, followed by recovery or even super-recovery of ozone and subsequent fall in incidence rates.

Acknowledgements-This work has been supported by the European Commission via the EC Integrated Project SCOUT-O3 (505390-GOCECT-2004).

\section{APPENDIX:}

\section{Dose-effect relations for skin cancer}

Dose-effect relations for people with a white skin. The doseeffect relations for skin cancer are used as presented by Slaper et al. (11) as a basis. These relations give the incidence for basal cell carcinoma (BCC), squamous cell carcinoma (SCC) and cutaneous melanoma $(\mathrm{CM})$ as a function of age a and the available annual doses of SCUP_h-weighted UV for people with a white skin $(66 \%$ skin reflectance at $685 \mathrm{~nm})$ :

$$
\operatorname{INC}(a)=Y(a)-Y(a-1)
$$

where yield $Y$ (the total number of tumors per million people observed in a population) is given by (values for coefficients $c$ and $d$ are given in Table 1):

$$
\begin{gathered}
Y_{\mathrm{SCC}}(a)=b(\phi(a))^{c} a^{d-c} \\
Y_{\mathrm{BCC}, \mathrm{CM}}(a)=b \sum_{\alpha=0}^{a-1} \operatorname{Dose}(\alpha)(\phi(\alpha))^{c-1}(a-\alpha)^{d-c}
\end{gathered}
$$

and where life-integrated UV dose $\phi(a)$ is given by the sum of all yearly doses:

$$
\phi(a) \equiv \sum_{\alpha=0}^{a-1} \operatorname{Dose}(\alpha)
$$

The dose received is assumed to be a fixed fraction of the available irradiance. Multiplicative factors $b$ are calibrated on the incidences (per million people per year) in Amsterdam in 1990: BCC:900, SCC:160, CM:110.

Dose-Effect Relations for Other Locations. Parkin et al. (23) reported the number of new cases of many types of cancer and the number of life-years-at-risk for a wide variety of countries over the world. The incidence rates for skin cancer that can be constructed from these figures vary strongly from country to country. Differences can be due to differences in local sensitivity, behavior and available UV-dose. Another factor that can lead to differences in reported incidence rates is underreporting, possibly related to a reduced access to medical care. To account in our model for the differences in reported incidence rates, we

Table 1. Parameters $c$ and $d$ in the empirical relations for skin cancer.

\begin{tabular}{lcc}
\hline Type of cancer & $c$ & $d$ \\
\hline BCC & $1.4 \pm 0.4$ & $4.9 \pm 0.6$ \\
SCC & $2.5 \pm 0.7$ & $6.6 \pm 0.4$ \\
CM & $0.6 \pm 0.4$ & $4.7 \pm 1.0$
\end{tabular}

$\overline{\mathrm{BCC} \text {, basal cell carcinoma; SCC, squamous cell carcinoma; CM, cutane- }}$ ous melanoma. 
introduce local dose-reduction factor $f_{\mathrm{p}}$ and local underregistration factor $f_{\mathrm{u}}$, both of which are set to 1 for the reference group in Amsterdam in 1990. The relation between the dose-effect model and reported incidence rates for location $x$ is thus:

$$
\begin{aligned}
\mathrm{INC}_{\text {reported }}(a, \text { Dose }, x) & =\frac{1}{f_{\mathrm{u}}(x)} \operatorname{INC}_{\text {model }}\left(a, \frac{\text { Dose }}{f_{\mathrm{p}}(x)}\right) \\
& =\frac{1}{f_{\mathrm{u}}(x) f_{\mathrm{p}}^{\mathrm{c}}(x)} \operatorname{INC}_{\text {model }}(a, \text { Dose })
\end{aligned}
$$

From the full set of incidence rates reported by Parkin et al., we selected those cancer registry stations that reported incidence rates for both melanoma and for at least one nonmelanoma of the skin. For each registry, we estimated the local climatologic mean SCUP_h-weighted, cloud corrected, year dose UVB and assumed that this dose has been stationary during the lives of the people contributing to the incidence figures. In this way, we calculated local model incidence estimates for melanoma and for (the reported kind(s) of) nonmelanoma, assuming neither dose reduction nor underregistration. For each station, the life-yearsat-risk from Parkin et al. is used as population distribution to construct age-integrated values for both the reported and for the modeled incidences. Equating modeled and reported age-integrated incidence rates via the above relation leads to a set of two equations for $f_{\mathrm{p}}$ and $f_{\mathrm{u}}$. The nonlinearity in $f_{\mathrm{p}}$ makes it possible to discriminate between dose reduction and incidence reduction and solve the equations. In this way, we estimated the values for $f_{\mathrm{p}}$ and $f_{\mathrm{u}}$ for each station that match model and observation.

\section{Skin Color as a Proxy for Dose Reduction}

With the just derived factors $f_{\mathrm{p}}$, we can use our dose-effect relation for the populations for which the cancer registry bureaus have given estimates for at least two types of skin cancer. This is not yet sufficient to construct worldwide estimates for skin cancer incidence. It has been shown that skins with different skin color provide different protection against erythema. Clydesdale et al. (42) report that "Increased melanin production provides increased protection against the harmful effects of UV exposure, to the extent that black people with a high melanin content, have a MED 33-fold higher than their Caucasian counterparts." Lucas et al. (39) observe that "intermediate skin types have intermediate values of protection." With respect to skin cancer, the incidence rates for subpopulations with a dark skin are way lower than for the fair-skinned subpopulations in the same area. This association motivates our suggestion that skin color can be a measure for protection against skin cancer. This finding does not explain why skin color is protective against skin cancer, only that it is a proxy for protection, whatever the exact nature of the mechanism. Kollias (43) found that "the photoprotection of epidermal melanin pigmentation is essentially independent of wavelength," in other words: skin pigmentation is a gray filter for UV radiation. This implies that skin pigmentation does not change the shape of action spectra and that it gives the same reduction in the action-spectrum-weighted UV dose for all UV-related effects that take place below the pigment layer. The skin may thus use its pigmentation-related protection against sunburn to also protect against skin cancer. The majority of (BCC + SCC) cases (often reported together in the incidence data that we used in our analysis) are related to BCC and both basal cells and melanocytes (involved in $\mathrm{CM}$ ) reside at the dermal/epidermal junction. If epidermal melanin pigmentation protects these cells by deferring a pigmentation-dependent fixed fraction of the incoming UV radiation to locations where less harm can be done, then one would expect the protection factors for $\mathrm{CM}$ and for $\mathrm{BCC}$, even though a different action spectrum may be involved, to be the same. In this way, the skin cancer-related dose-reduction factor can be assumed to be the same for all types of skin cancer. This is exactly what we did when we estimated dose-reduction factors $f_{\mathrm{p}}$ for each cancer registry. Further elaboration of this approach requires a worldwide model for local skin color.

We use skin reflectances at $685 \mathrm{~nm}$ as a measure for skin color. Local skin reflectance is estimated as a linear combination of the locally available ethnic groups, weighted with their fractional contributions to the local population (44). Original, indigenous skin reflectance of each ethnic group has been modeled according to Chaplin and Jablonski $(41,45)$. These predictions were combined with data on ethnic composition in each country (44). We estimate the local skin reflectances for the cancer registry bureaus for which we estimated $f_{\mathrm{p}}$. The relation between $f_{\mathrm{p}}$ and local skin reflectance is presented in Fig. 10a.
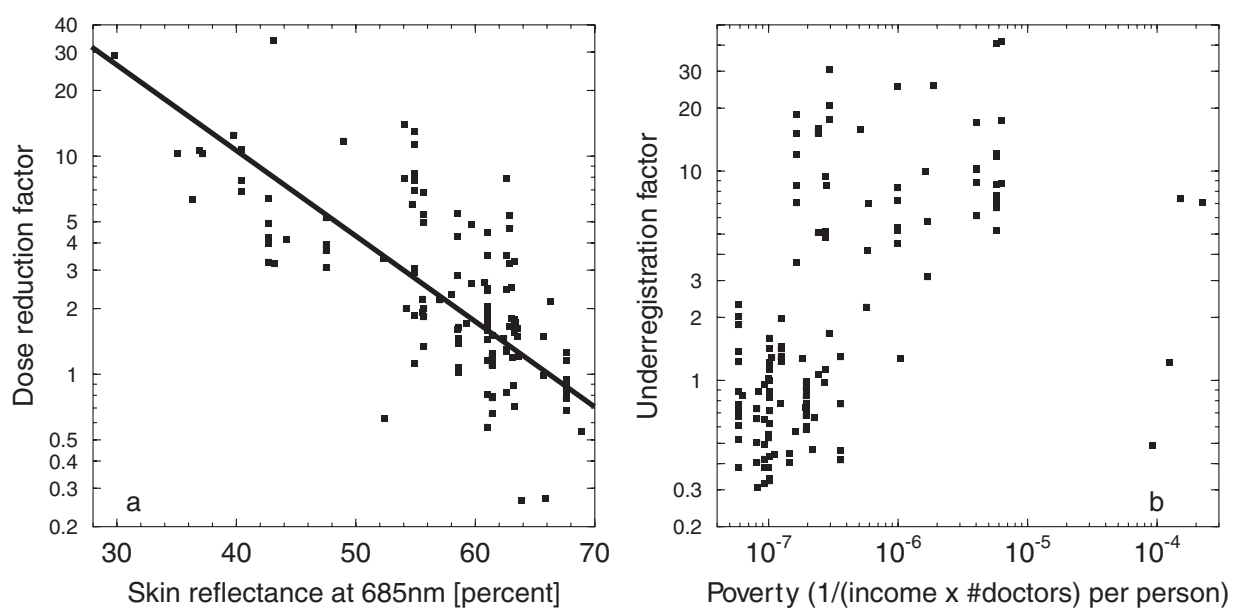

Figure 10. (a) Dose reduction as a function of skin reflectance. The line is a fit of the log of the reduction factor as a function of skin reflectance forced through a dose reduction of 1 for $66 \%$ skin reflectance. (b) Underregistration associated with registry data used for estimation of dose reduction, as a function of poverty. 
The dashed line shown is the regression curve for log (dose reduction) as a function of skin reflectance, forced through the calibration of our original model:

$$
f_{\mathrm{p}}=10^{a\left(x-x_{0}\right)}
$$

where $x_{0}=66$ denotes the reference skin reflectivity of white people, whom we set to have a reference protection of one. Thus, for white Caucasians the generalized dose-effect relations reduce to the original relations from Slaper et al. By fitting the worldwide skin cancer incidence data from Parkin et al. (23), we found $a=-0.03935$. For dark skin (reflectivity $30 \%$ ), this model gives a protection factor of $f_{\mathrm{p}}=26$. This is very similar to the 33 -fold lower MED value reported by Clydesdale et al. (40).

In our analysis, we have used underregistration factor $f_{\mathrm{u}}$. We still have to check plausibility of the values found. Underregistration is likely to happen when people have reduced access to medical care. This may be because they live in poverty and cannot pay for a doctor, or because there are too few doctors available. We used the data from (44) to construct a poverty measure as follows:

\section{Poverty $=1 /$}

([income per person per year $] \times[$ no. physicians per 1000 people $]$ )

The relation between poverty and $f_{\mathrm{u}}$ is presented in Fig. 10b. The lion's share of the plot is formed by a big cloud of data with strong correlation between poverty and underregistration. Four samples for stations with very large poverty have relatively mild underregistration when compared with the other samples.

Altogether, the above dose-effect relations are now generalized to all skin types with a dose-reduction factor $f_{\mathrm{p}}$, accounting for local UV sensitivity, as a function of skin reflectivity $\mathrm{x}$ at $685 \mathrm{~nm}$ :

$$
\begin{aligned}
\text { Dose }_{\text {local sensitivity }} & =\frac{\text { Dose }_{\text {reference sensitivity }}}{f_{\mathrm{p}}} \\
f_{\mathrm{p}} & =10^{-0.03935(x-66)}
\end{aligned}
$$

\section{REFERENCES}

1. Fabry, C. and H. Buisson (1913) L'absorption de l'ultraviolet par l'ozone et la limite du spectre solaire. J. Phys. Rad. 3(5), 196-206.

2. Chapman, S. (1931) Absorption and dissociative or ionising effects of monochromatic radiation in an atmosphere on a rotating earth. Proc. Phys. Soc. London 43, 1047-1055.

3. Blankenship, J. R. and P. J. Crutzen (1965) A photochemical model for the space-time variations of the oxygen allotropes in the 20 to $100 \mathrm{~km}$ layer. Tellus 18, 160-175.

4. Crutzen, P. J. (1970) The influence of nitrogen oxides on the atmospheric ozone content. Quart. J. Roy. Meteor. Soc. 96, 320-325.

5. Molina, M. J. and F. S. Rowland (1974) Stratospheric sink for chlorofluoromethanes: Chlorine atom-catalyzed destruction of ozone. Nature 249, 810-812.

6. Crutzen, P. J. (1974) Estimates of possible future ozone reductions from continued use of fluorochloromethanes $(\mathrm{CF} 2 \mathrm{Cl} 2, \mathrm{CFCl} 3)$. Geophys. Res. Lett.. 1, 205-208.

7. Farman, J. C., B. G. Gardiner and J. D. Shanklin (1985) Large losses of total ozone in Antarctica reveal seasonal C1Ox/NOx interaction. Nature 315, 207-210.

8. World Meteorological Organization (WMO)/United Nations Environment Programme (UNEP) (2003) Scientific assessment of ozone depletion: 2002. Global Ozone Res. Monit. Proj. Rep. 47, 498. Geneva, Switzerland

9. United Nations Environment Programme (UNEP) (2006) Handbook for the Montreal Protocol on Substances that Deplete the Ozone Layer -7th Edition (2006) as adjusted and amended by the Second Meeting of the Parties (London, 27-29 June 1990) and by the Fourth Meeting of the Parties (Copenhagen, 23-25 November 1992) and further adjusted by the Seventh Meeting of the Parties (Vienna, 5-7 December 1995) and further adjusted and amended by the Ninth Meeting of the Parties (Montreal, 15-17 September 1997) and by the Eleventh Meeting of the Parties (Beijing, 29 November-3 December 1999). Available at: http://ozone.unep.org/Publications/MP_Handbook/Section_1.1_The_Montreal_Protocol/. Accessed on 21 May 2012.

10. World Meteorological Organization (WMO) (2011), Scientific assessment of ozone depletion: 2010. Global Ozone Res. Monit. Proj. Rep. 52, 516. Geneva, Switzerland.

11. Slaper, H., G. J. M. Velders, J. S. Daniel, F. R. de Gruijl and J. C. van der Leun (1996) Estimates of ozone depletion and skin cancer incidence to examine the Vienna convention achievements. Nature 384(6606), 256-258.

12. Slaper, H., J. Matthijsen, P. N. den Outer and G. J. M. Velders (2001) Climatology of Ultraviolet Budgets using Earth Observation (CUBEO): Mapping UV from the perspective of risk assessments. USP-2 00-17, USP-2 project 4.1/AP-03, ISBN 90541132 6, Netherlands Remote Sensing Board (BCRS), Delft, The Netherlands. Available at: http://www.rivm.nl/bibliotheek/rapporten/000200101. html. Accessed on 21 May 2012.

13. Kelfkens, G., P. N. den Outer and H. Slaper (2001) Risks and Ultraviolet Budgets using Earth Observation (RUBEO): Including a nonstandard atmosphere and geographic ozone trend differences in risk assessments. USP-2 01-33, USP-2 project 4.1/DE-02, ISBN 9054 11378 2, Netherlands Remote Sensing Board (BCRS), Delft, The Netherlands. Available at: http://www.rivm.nl/bibliotheek/rapporten/ 000200102.html. Accessed on 21 May 2012.

14. Van Dijk, A., P. N. den Outer and H. Slaper (2008) Climate and Ozone change Effects on Ultraviolet radiation and Risks (COEUR) using and validating earth observations. RIVM Report 610002001, RIVM, Bilthoven, The Netherlands. Available at: http://www.rivm. nl/bibliotheek/rapporten/610002001.html. Accessed on 21 May 2012.

15. Struijs, J., A. van Dijk, H. Slaper, H. J. van Wijnen, G. J. M. Velders, G. Chaplin and M. A. J. Huijbregts (2010) Spatial- and timeexplicit human damage modelling of ozone depleting substances in life cycle impact assessment. Environ. Sci. Technol. 44, 204-209.

16. United Nations Environment Programme, Environmental Effects Assessment Panel (2012) Environmental effects of ozone depletion and its interactions with climate change: Progress report 2011. Photochem. Photobiol. Sci. 11(1), 13-27.

17. Morgenstern, O., P. Braesicke, M. M. Hurwitz, F. M. O'Connor, A. C. Bushell, C. E. Johnson and J. A. Pyle (2008) The world avoided by the Montreal protocol. Geophys. Res. Lett. 35, L16811. (DOI: 10.1029/2008GL034590)

18. Morgenstern, O., P. Braesicke, F. M. O'Connor, A. C. Bushell, C. E. Johnson, S. M. Osprey and J. A. Pyle (2009) Evaluation of the new UKCA climate-composition model-Part 1: The stratosphere. Geosci. Model Dev. 2, 43-57.

19. Stenke, A., M. Dameris, V. Grewe and H. Garny (2009) Implications of Lagrangian transport for simulations with a coupled chemistry-climate model. Atmos. Chem. Phys. 9, 5489-5504.

20. Garny, H., M. Dameris and A. Stenke (2009) Impact of prescribed SSTs on climatologies and long-term trends in CCM simulations. Atmos. Chem. Phys. Discuss. 9, 4489-4524.

21. SPARC CCMVal (2010), SPARC CCMVal Report on the Evaluation of Chemistry-Climate Models (Edited by V. Eyring, T. G. Shepherd and D. W. Waugh), SPARC Report No. 5, WCRP-132, WMO/ TD-No. 1526. Available at: http://www.atmosp.physics.utoronto.ca/ SPARC/ccmval final/index.php. Accessed on 21 May 2012.

22. Newman, P. A. and R. McKenzie (2011) UV impacts avoided by the Montreal protocol. Photochem. Photobiol. Sci. 10, 1152-1160.

23. Parkin, D. M., S. L. Whelan, J. Ferlay, L. Teppo and D. B. Thosmas (2002) Cancer Incidence in Five Continents, Vol. VIII. IARC Scientific Publications No. 155, Lyon, France

24. Pitcher, H. M. and J. D. Longstreth (1991) Melanoma mortality and exposure to ultraviolet radiation: An empirical relationship. Environ. Int. 17, 7-21. 
25. Outer, P. N. den, H. Slaper, A. Lindfors, J. Kaurola, A. Bais, A. Kazantzidis, U. Feister, J. Junk, M. Janouch and W. Josefsson (2010) Reconstructing of erythemal ultraviolet radiation levels in Europe for the past four decades. J. Geophys. Res. 115, D10102.

26. Matthijsen, J., H. Slaper, H. A. J. M. Reinen and G. J. M. Velders (2000) Reduction of solar UV by clouds: A comparison between satellite-derived effects and ground-based radiation measurements. J. Geophys. Res. 105, 5069-5080.

27. Williams, J. E., P. N. Den Outer, H. Slaper, J. J. Matthijsen and G. Kelfkens (2004) Cloud induced reduction of solar UV radiation: A comparison of ground-based and satellite based approaches. Geophys. Res. Lett. 31(3), L03104.

28. Outer, P. N. den, H. Slaper and R. B. Tax (2005) UV radiation in the Netherlands: Assessing long-term variability and trends in relation to ozone and clouds. Geophys. Res. 110, D02203.

29. Madronich, S.. (1998) The TUV software package version 4.1a. Available at: http://cprm.acd.ucar.edu/Models/TUV/. Accessed on 21 May 2012.

30. Bernhard, G., C. R. Booth and J. C. Ehramjian (2004) Version 2 data of the National Science Foundation's Ultraviolet Radiation Monitoring Network: South Pole. J. Geophys. Res 109, D21207. Available at: http://uv.biospherical.com/Version2/description-Version2-Database3.html. Accessed on 7 June 2012. (DOI: 10.1029/ 2004JD004937)

31. U.S. Census Bureau (2004) Global Population Profile: 2002. International Population Reports WP/02, U.S. Government Printing Office, Washington, DC. Available at: http://www.census.gov/prod/ 2004pubs/wp-02.pdf. Accessed on 7 June 2012.

32. United Nations (1998) World Population Projections to 2150. United Nations Department of Economic and Social Affairs Population Division, New York.

33. United Nations (1966) World Population Prospects as Assessed in 1963. United Nations Department of Economic and Social Affairs Population Division, New York.

34. UT-Battelle, LLC, operator of Oak Ridge National Laboratory (2002) LandScan High Resolution global Population Data Set, Contract No. DE-AC05-00OR22725 with the United States Department of Energy. Available at: http://www.ornl.gov/sci/landscan/index. shtml. Accessed on 8 June 2012.

35. Newman, P. A., L. D. Oman, A. R. Douglass, E. L. Fleming, S. M. Frith, M. M. Hurwitz, S. R. Kawa, C. H. Jackman, N. A. Krotkov, E. R. Nash, J. E. Nielsen, S. Pawson, R. S. Stolarski and G. J. M. Velders (2009) What would have happened to the ozone layer if chlorofluorocarbons (CFCs) had not been regulated? Atmos. Chem. Phys. 9, 2113-2128.

36. Loyola, D. G., R. M. Coldewey-Egbers, M. Dameris, H. Garny, A. Stenke, M. van Roozendael, C. Lerot, D. Balis and M. Koukouli (2009) Global long-term monitoring of the ozone layer-A prerequisite for predictions. Int. J. Remote Sens. 30, 15-16, 4295-4318. (DOI: $10.1080 / 01431160902825016)$
37. Bais, A. F., K. Tourpali, A. Kazantzidis, H. Akiyoshi, S. Bekki, P. Braesicke, M. P. Chipperfield, M. Dameris, V. Eyring, H. Garny, D. Iachetti, P. Jockel, A. Kubin, U. Langematz, E. Mancini, M. Michou, O. Morgenstern, T. Nakamura, P. A. Newman, G. Pitari, D. A. Plummer, E. Rozanov, T. G. Shepherd, K. Shibata, W. Tian and Y. Yamashita (2011) Projections of UV radiation changes in the 21st century: Impact of ozone recovery and cloud effects. Atmos. Chem. Phys. 11, 7533-7545. Available at: www.atmos-chem-phys.net/11/ 7533/2011/. (DOI: 10.5194/acp-11-7533-2011)

38. Morgenstern, O., M. A. Giorgetta, K. Shibata, V. Eyring, D. W. Waugh, T. G. Shepherd, H. Akiyoshi, J. Austin, A. J. G. Baumgaertner, S. Bekki, P. Braesicke, C. Brühl, M. P. Chipperfield, D. Cugnet, M. Dameris, S. Dhomse, S. M. Frith, H. Garny, A. Gettelman, S. C. Hardiman, M. I. Hegglin, P. Jöckel, D. E. Kinnison, J. -F. Lamarque, E. Mancini, E. Manzini, M. Marchand, M. Michou, T. Nakamura, J. E. Nielsen, D. Olivié, G. Pitari, D. A. Plummer, E. Rozanov, J. F. Scinocca, D. Smale, H. Teyssèdre, M. Toohey, W. Tian and Y. Yamashita (2010) Review of the formulation of present-generation stratospheric chemistry-climate models and associated external forcings. J. Geophys. Res.-Atmos. 115, D00M02. (DOI: 10.1029/2009jd013728)

39. Lucas, R., T. McMichael, W. Smith and B. Armstrong (2006) Solar Ultraviolet Radiation, Global burden of disease from solar ultraviolet radiation. Environmental Burden of Disease Series, No. 13 (Edited by A. Prüss-Üstün, H. Zeeb, C. Mathers and M. Repacholi), 250pp. World Health Organization, Public Health and the Environment, Geneva. Available at: http://www.who.int/uv/health/solaruvradfull_180706.pdf. Accessed on 10 September 2012.

40. Manney, G. L., M. L. Santee, M. Rex, N. J. Livesey, M. C. Pitts, P. Veefkind, E. R. Nash, I. Wohltmann, R. Lehmann, L. Froidevaux, L. R. Poole, M. R. Schoeberl, D. P. Haffner, J. Davies, V. Dorokhov, H. Gernandt, B. Johnson, R. Kivi, E. Kyrö, N. Larsen, P. F. Levelt, A. Makshtas, C. T. McElroy, H. Nakajima, M. C. Parrondo, D. W. Tarasick, P. von der Gathen, K. A. Walker and N. S. Zinoviev (2011) Unprecedented Arctic ozone loss in 2011. Nature 478, 469-475.

41. Jablonski, N. G. and G. Chaplin (2000) The evolution of human skin coloration. J. Hum. Evol. 39, 57-106.

42. Clydesdale, G. J., G. W. Dandie and H. K. Muller (2001) Ultraviolet light induced injury: Immunological and inflammatory effects. Immunol. Cell Biol. 79, 547-568.

43. Kollias, N., Y. H. Malallah, H. Al-Ajmi, A. Baqer, B. E. Johnson and S. González (1996) Erythema and melanogenesis action spectra in heavily pigmented individuals as compared to fair-skinned Caucasians. Photodermatol. Photoimmunol. Photomed. 12-15, 183-188.

44. Central Intelligence Agency (2005) The world factbook. Available at: https://www.cia.gov/library/publications/the-world-factbook/index. html. Accessed on 8 June 2012.

45. Chaplin, G. (2004) Geographic distribution of environmental factors influencing human skin coloration. Am. J. Phys. Anthropol. 125, 292-302. 